\title{
PENGARUH TERAPI KOMBINASI 5 TITIK AKUPUNKTUR TERHADAP PENURUNAN JUMLAH RAMBUT RONTOK (ALOPECIA ANDROGENETIC) PADA WANITA USIA 31-50 TAHUN
}

\author{
Norma Dyanti Aisyah
}

\begin{abstract}
ABSTRAK
Alopecia androgenetic pada wanita, dikenal dengan female pattern hair loss. Alopecia dapat memberikan dampak negatif terhadap penderita, baik secara fisik, psikologik maupun kosmetik.Penanganan alopecia dapat dilakukan menggunakan pengobatan konvensional dan tradisional. Salah satu cara pengobatan tradisional menggunakan terapi akupunktur memakai titik Baihui (GV20), Sishenchong (EX- HN1), Taixi (KI3), Taiyuan (LU9) dan Taichong (LV3). Penelitian ini merupakan penelitian pra eksperimental menggunakan prepost test group design. Penelitian dilakukan pada tanggal 19 Desember 2016 sampai 21 Januari 2017 di tempat tinggal dan tempat kerja subyek penelitian. Jumlah subyek 10 orang. Sebelum dan sesudah perlakuan dilakukan hair pull test pada subyek penelitian. Data yang diperoleh dianalisis menggunakan $T$ test dengan memakai program SPSS. Hasil penelitian menunjukkan jumlah hair pull test sebelum dan sesudah memiliki perbedaan bermakna (nilai $\mathrm{p}=0,018$ dengan mean value 1.10 dan konfiden interval 95\%). Berdasarkan hasil tersebut, dapat disimpulkan bahwa pemberian terapi akupunktur pada titik Baihui (GV20), Sishencong (EX-HN 1), Taixi (KI3), Taiyuan (LU9) dan Taichong (LV3) berpengaruh menurunkan jumlah rambut rontok pada wanita usia 31-50 tahun $(p<0,05)$.
\end{abstract}

Kata Kunci: Alopecia androgenetic, Wanita, Akupunktur

\section{Latar Belakang}

Dalam dunia kedokteran

penyakit rambut rontok disebut

alopecia (Guerrero dan Kahn, 2011).

Alopecia adalah salah satu penyakit kulit

yang masih merupakan masalah dalam

menentukan penyebab maupun cara

mengobatinya. Alopecia dapat memberikan dampak negatif terhadap penderita, baik secara fisik, psikologik maupun kosmetik (Putra, 2008).

Alopecia ini berkaitan dengan faktor predisposisi genetik dan adanya jumlah androgen yang cukup pada sirkulasi. Siklus folikel rambut pada scalp mengalami transformasi dari fase pertumbuhan (anagen) yang panjang 
Jurnal Biosains Pascasarjana Vol. 21 (2019) pp

(C) (2019) Sekolah Pascasarjana Universitas Airlangga, Indonesia

dan fase istirahat (telogen) yang

pendek, menjadi fase istirahat yang

panjang dan fase pertumbuhan yang

pendek (Utami, 2015).

Berdasarkan mekanisme

terjadinya, Alopecia dibagi menjadi

dua kelompok yaitu Alopecia

Sikratikal dan Alopecia Non Sikratikal

atau lebih dikenal dengan Alopecia

Scarring dan Alopecia Non Scarring.

Kelompok Alopecia Non Sikratikal

meliputi alopecia androgenetic,

alopecia areata serta alopecia traumatic

(Putra, 2008).

Alopecia androgenetic pada

wanita, dikenal dengan female pattern

hair loss. Pada wanita, penipisan rambut

terjadi secara acak, tetapi tampak paling

nyata pada bagian frontal atau parietal

kulit kepala (Pratiwi, dkk., 2013).

Alopecia androgenetic menurut

Traditional Chinese Medicine (TCM)

adalah kerontokan rambut yang dapat

disebabkan karena ekses panas/api sehingga

menimbulkan angin, stasis $q i$ dan

darah, defisiensi $q i$ dan darah, serta berhubungan erat dengan organ ginjal

(Boldrin, 2010).

Prevalensi di Korea, untuk

wanita Alopecia andogenetic

klasifikasi Ludwig I, usia 30 tahun

sebanyak 5,8\%, usia 40 tahun sebanyak

$7,9 \%$, usia 50 tahun sebanyak 9,4\%.

Prevalensi wanita AGA di China sebanyak $3,1 \%$ dengan tipe paling banyak Ludwig I yaitu $1,4 \%$ (Lee, et al., 2012). Angka kejadian rambut rontok pada wanita lebih banyak ditemukan pada wanita pascamenopause (Sawitri, dkk., 2009).

Data rekam medik Divisi

Kosmetik URJ Kesehatan Kulit dan

Kelamin RSUD Dr. Soetomo menunjukkan jumlah pasien baru alopecia androgenetic selama periode 2009-2011 sebanyak 91 orang. Data kunjungan pasien rawat jalan di URJ Kesehatan Kulit dan Kelamin periode Januari 2010-Oktober 2013 menyebutkan bahwa jumlah pasien baru alopecia sebanyak 338 orang (Paramita, dkk., 2015). 
Jurnal Biosains Pascasarjana Vol. 21 (2019) pp

(C) (2019) Sekolah Pascasarjana Universitas Airlangga, Indonesia

Pada wanita yang menggunakan kerudung, rambut tertutup dalam waktu yang cukup lama sehingga menyebabkan rambut kekurangan oksigen, lembab dan panas. Penggunaan kerudung pada dasarnya bukanlah menjadi penyebab dari terganggunya kesehatan rambut wanita berkerudung namun sikap dalam menjaga kesehatan rambutlah yang harus diperhatikan dan dapat menjadi penyebab dari permasalahan rambut (Arisandi, 2014).

Menurut prevalensi di Asia (Lee, et al., 2012), kasus alopecia androgenetic paling banyak dialami oleh wanita usia 31-50 tahun. Pada buku (dalam Abdurachman, 2016) dijelaskan bahwa $Q i$ ginjal tumbuh dengan subur pada wanita di usia 14 tahun, ketika wanita mulai menstruasi, menandakan kesiapan untuk menghasilkan keturunan. Pada waktu wanita mencapai usia 28 tahun, $Q i$ ginjal mencapai puncaknya, tubuh berkembang dengan subur, mencapai kehidupan yang prima. Pada waktu wanita mencapai usia 49 tahun, maka $Q i$ ginjal akan melemah, tubuh mulai lemah dan pada saat bersamaan organ reproduksi tidak berfungsi lagi.

Secara kedokteran konvensional, alopecia diterapi menggunakan terapi obat-obatan dan transplantasi rambut. Minoxidil dan Propecia (Finasteride) yaitu dua obat yang disetujui oleh Food and Drug Administration (FDA) untuk pertumbuhan rambut pada pria dan wanita. Obat ini telah terbukti menunjukkan hasil yang positif untuk kebotakan di wilayah kulit kepala. Meskipun obat ini efektif, banyak yang waspada terhadap efek jangka panjang obat tersebut. Hal ini menyebabkan peningkatan minat dalam pengobatan alternatif (Patil, et al., 2010).

Penanganan rambut rontok dapat dilakukan dengan pengobatan secara konvensional dan tradisional. Salah satu cara pengobatan tradisional adalah terapi akupunktur. Menurut Traditional Chinese Medicine (TCM), rambut merupakan manifestasi dari Shenginjal. Rambut berwarna hitam dan 
Jurnal Biosains Pascasarjana Vol. 21 (2019) pp

(C) (2019) Sekolah Pascasarjana Universitas Airlangga, Indonesia

tebal merupakan ekspresi $Q i$ dari Shen-

ginjal subur, Jing dan Xue-darah cukup.

Sebaliknya, rambut menjadi kuning,

tipis dan kering sebagai pertanda

Jing dan Xue-darah tidak cukup. Pada

penderita yang lemah sekali, sering

dijumpai secara mendadak rambut

rontok pada seluruh daerah kepala atau

pada satu tempat. Keadaan itu umumnya

disebabkan oleh Xue-darah kurang dan

terserang patogen angin (Jie, 1997).

Dalam jurnal (Lee, et al., 2015)

disebutkan titik-titik akupunktur yang

dapat digunakan untuk terapi

kerontokan rambut, antara lain: Baihui

(GV20), Taixi (KI3), Taichong (LV3)

dan Sishenchong (EX-HN1). Dalam

buku (Xu, 2004) disebutkan titik-titik

akupunktur yang dapat digunakan

untuk terapi kerontokan rambut yaitu

Taichong (LV3) Taixi (KI3) dan

Taiyuan (LU9).

Berdasarkan latar belakang tersebut, selanjutnya peneliti ingin membuktikan apakah kombinasi titik Baihui (GV20), Sishenchong (EX-HN1),
Taixi (KI3), Taiyuan (LU9) dan

Taichong (LV3) dapat mengurangi jumlah rambut rontok (alopecia androgenetic) pada wanita usia 31-50 tahun.

H
$\mathbf{a}$
$\mathbf{s}$
$\mathbf{i}$
$\mathbf{l}$
$\mathbf{P}$
$\mathbf{e}$
$\mathbf{n}$
$\mathbf{e}$
$\mathbf{l}$
$\mathbf{i}$
$\mathbf{t}$
$\mathbf{i}$
$\mathbf{a}$
$\mathbf{n}$

Penelitian ini berlangsung selama 5 minggu. Terhitung sejak 19 Desember 2016 hingga 21 Januari 2017 di tempat kerja dan tempat tinggal responden di Surabaya. Pada penelitian ini dilakukan anamnesa, pemeriksaan fisik lidah dan nadi serta pemeriksaan hair pull test pada 16 orang. Didapatkan 12 orang yang memiliki hasil hair pull test $>5$ helai rambut. Dua belas orang tersebut diberikan terapi akupunktur pada titik Baihui (GV20), Sishenchong (EX-HN1), Taixi (KI3), Taiyuan (LU9) dan Taichong (LV3). Namun 
Jurnal Biosains Pascasarjana Vol. 21 (2019) pp

(C) (2019) Sekolah Pascasarjana Universitas Airlangga, Indonesia

dalam proses penelitian terdapat 2 orang jenis kelamin dan usia. Berdasarkan yang tidak dapat melanjutkan terapi jenis kelamin seluruh responden (100\%)

karena alasan tertentu. Sehingga sampel berjenis kelamin perempuan (10 orang).

awal yaitu 12 responden, hanya menjadi 10 Berdasarkan usia, responden dengan

responden, karena 2 responden yang tidak usia 31-40 tahun sebanyak 5 orang

dapat melanjutkan terapi dinyatakan gugur. $\quad(50 \%), 41-50$ tahun sebanyak 5 orang

Gambar

an

Umum

Respon

den

Peneliti

an

Responden dalam penelitian

\begin{tabular}{|l|r|r|}
\hline \multicolumn{1}{|c|}{$\mathbf{U}$} & Jumlah (Subyek & Persentase (\%) \\
\hline $31-40$ tahun & 5 & 50,0 \\
$41-50$ tahun & 5 & 50,0 \\
\hline Total & 1 & 100,0 \\
\hline
\end{tabular}

Tabel 5.2 Pekerjaan Responden

terdiri dari perempuan yang memiliki

rentang usia 31 - 47 tahun. Mereka

menderita rambut rontok dengan hasil

hair pull test $>5$ helai rambut. Di bawah

ini adalah gambaran umum responden

$(50 \%)$

Tabel 5.1 Gambaran Umum Responden

\begin{tabular}{|l|c|c|}
\hline \multicolumn{1}{|c|}{ Pekerjaan } & Jumlah (Subyek & Persentase (\%) \\
\hline Perawat & 3 & $30 \%$ \\
\hline Bidan & 1 & $10 \%$ \\
\hline Wirausaha & 2 & $20 \%$ \\
\hline Ibu Rumah Tangga & 4 & $40 \%$ \\
\hline in Jumlah & 1 & $100 \%$ \\
\hline
\end{tabular}

\section{Uji Normalitas Data}

Uji normalitas menggunakan Shapiro-Wilk setelah 5 kali dan 10 kali terapi menunjukkan nilai $\mathrm{p}$ lebih besar dari $\alpha$ 0,05 sehingga data berdistribusi normal dan memenuhi syarat untuk menggunakan Uji T. Untuk selanjutnya

\begin{tabular}{|c|c|c|c|c|c|}
\hline \multirow{2}{*}{ Kelompok } & \multirow{2}{*}{$\mathrm{N}$} & \multicolumn{2}{|c|}{ Hasil Hair Pull Test } & \multicolumn{2}{|c|}{ Uji T } \\
\hline & & Rerata & $\mathrm{SD}$ & Signifikansi & Kesimpulan \\
\hline $\begin{array}{l}\text { Pretest } \\
\text { Postest }\end{array}$ & $\begin{array}{l}12 \\
10\end{array}$ & $\begin{array}{c}11,40 \\
1,10\end{array}$ & $\begin{array}{l}2,17 \\
1,10\end{array}$ & \multirow[t]{2}{*}{$\mathrm{p}=0.018$} & \multirow{2}{*}{$\begin{array}{l}\text { Ada beda } \\
\text { bermakna }\end{array}$} \\
\hline Jumlah & 10 & 10,30 & 1,56 & & \\
\hline
\end{tabular}

Tabel 5.1 dibawah menunjukkan

karakteristik responden berdasarkan dan tabel uji statistik menggunakan

$T$ Test dapat di lihat pada lampiran 9 dan

10. 
Jurnal Biosains Pascasarjana Vol. 21 (2019) pp

(C) (2019) Sekolah Pascasarjana Universitas Airlangga, Indonesia

\section{Uji Statistik}

Tabel 5.3 Hasil Uji Statistik

Dari tabel 5.3 hasil uji statistik diatas, tampak perbedaan yang bermakna pada rerata hair pull test sebelum dan sesudah diberi terapi akupunktur, mean value pretest $=11.40$, sedangkan mean value posttest $=1.10 . P$ values $=0,018$ dengan confident interval $95 \%$.

\section{Pembahasan}

Berdasarkan tabel hasil penelitian, responden memiliki ratarata hasil hair pull test sebelum terapi yaitu 11,4. Hasil hair pull test $>5$ helai rambut mengindikasikan responden mengalami Alopecia. Setelah diberikan 10 kali terapi responden memiliki rata-rata hasil hair pull test yaitu 1.1, sehingga responden bukan termasuk yang diindikasikan mengalami Alopecia karena hasil hair pull test 0-2 helai dinyatakan normal.

Pada tabel 5.2 memperlihatkan bahwa pemberian terapi akupunktur sebanyak 10 kali terapi menggunakan titik Baihui (GV20), Sishenchong (EXHN1), Taixi (KI3), Taiyuan (LU9) dan Taichong (LV3) memiliki perbedaan yang bermakna. Hasil statistik menunjukan $p$ value $0,018<\alpha(0,05)$. Ini menunjukkan terapi akupunktur menggunakan titik tersebut berpengaruh menurunkan jumlah rambut rontok dari hasil hair pull test dengan tingkat perbaikan sebesar 90,35\% (lampiran 6).

Pengaruh yang signifikan terhadap penurunan jumlah rambut rontok menggunakan terapi akupunktur sejalan dengan sebuah studi yang dilakukan oleh Chun (1995) yang menunjukkan akupunktur spesifik dengan atau tanpa rangsangan listrik untuk pengobatan alopecia androgenetic laki-laki dan perempuan. Pengujian menunjukkan hasil positif yaitu $95 \%$ dari peserta tanpa memandang usia dan ras mengalami penghentian rambut rontok rata-rata 2-4 minggu setelah pengobatan awal.

Menurut Traditional Chinese Medicine (TCM), rambut merupakan 
Jurnal Biosains Pascasarjana Vol. 21 (2019) pp

(C) (2019) Sekolah Pascasarjana Universitas Airlangga, Indonesia

manifestasi dari Shen-ginjal. Rambut berwarna hitam dan tebal merupakan ekspresi Qi dari Shen-ginjal subur, Jing dan Xue-darah cukup. Sebaliknya, rambut menjadi kuning, tipis dan kering sebagai pertanda Jing dan Xue-darah tidak cukup (Jie, 1997).

Asal mula Xue dan Jing yaitu dari hasil makanan dan minuman. Seluruh tubuh manusia, rambut, kulit, tulang, otot maupun Zhang $F u$, tanpa adanya Xue dan Jing tidak mungkin dapat bekerja. Hati memiliki fungsi fisiologis utama sebagai penyimpan dan

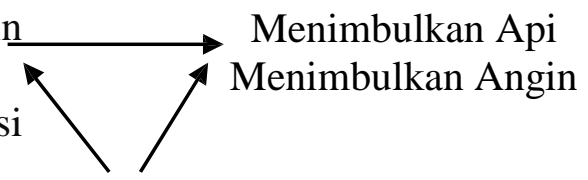
Ekses Yang Hati pengatur Xue dan memelihara aliran $q i$,

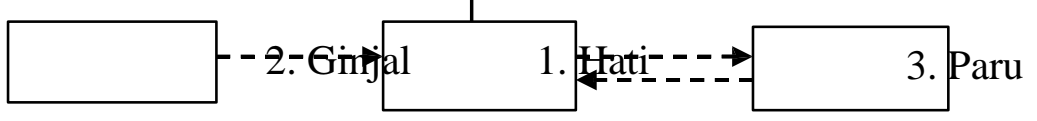


Jurnal Biosains Pascasarjana Vol. 21 (2019) pp

(C) (2019) Sekolah Pascasarjana Universitas Airlangga, Indonesia

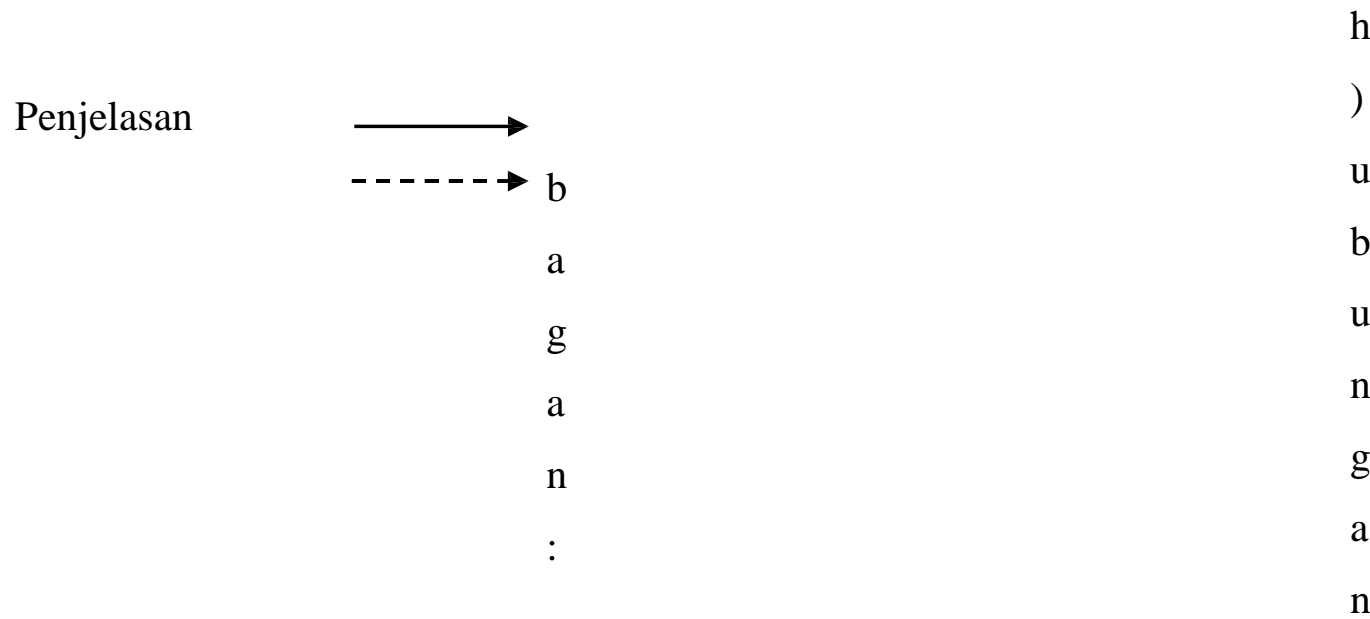

b

a

d

a

Gambar 5.1 Bagan Hubungan Hati dengan Organ Zhang lain (San, dkk., 1985).

1. Karena Hati dalam keadaan $S e$, maka 1

Yang Hati menjadi terlalu kuat. Hal ini

nhenyebabkan terjadinya Api dan Angin.

a 
Jurnal Biosains Pascasarjana Vol. 21 (2019) pp

(C) (2019) Sekolah Pascasarjana Universitas Airlangga, Indonesia

2. Karena Yin Ginjal kurang Air sehingga tidak bisa menyuburkan kayu.

3. Hubungan peraturan $W u$ Xing antara

Hati dan Paru. Hati yang ekses sehingga menghina Paru.

Mekanisme terapi akupunktur pada penelitian ini adalah akupunktur dapat mengeliminasi panas dan angin dari Hati dan Paru karena faktor penyebab penyakit dalam (PPD) emosi dan penyebab penyakit luar (PPL) makanan pedas dan panas. Angin mengarah ke kekurangan gizi pada kulit kepala (darah dan yin), yang menyebabkan rambut rontok. Apabila panas PPD (Emosi, Depresi) dan angin dari Hati dan Paru berkurang, maka peredaran darah akan lancar dan tidak terjadi stagnasi $q i$ dan darah. Akupunktur juga dapat menguatkan Yin Ginjal, karena panas dari Hati dapat menjadikan Ginjal kekurangan nutrisi sehingga tidak dapat menyuburkan rambut, maka selain menghilangkan penyebab penyakit, akupunktur dapat menguatkan organ yang lemah karena ditindas organ yang berlebihan.

PPL (Makanan

Pedas \& panas) 
Jurnal Biosains Pascasarjana Vol. 21 (2019) pp

(C) (2019) Sekolah Pascasarjana Universitas Airlangga, Indonesia

$\begin{array}{cc}\text { Ekses Yang } & \text { Rambut } \\ \text { Paru } & \text { Rontok }\end{array}$

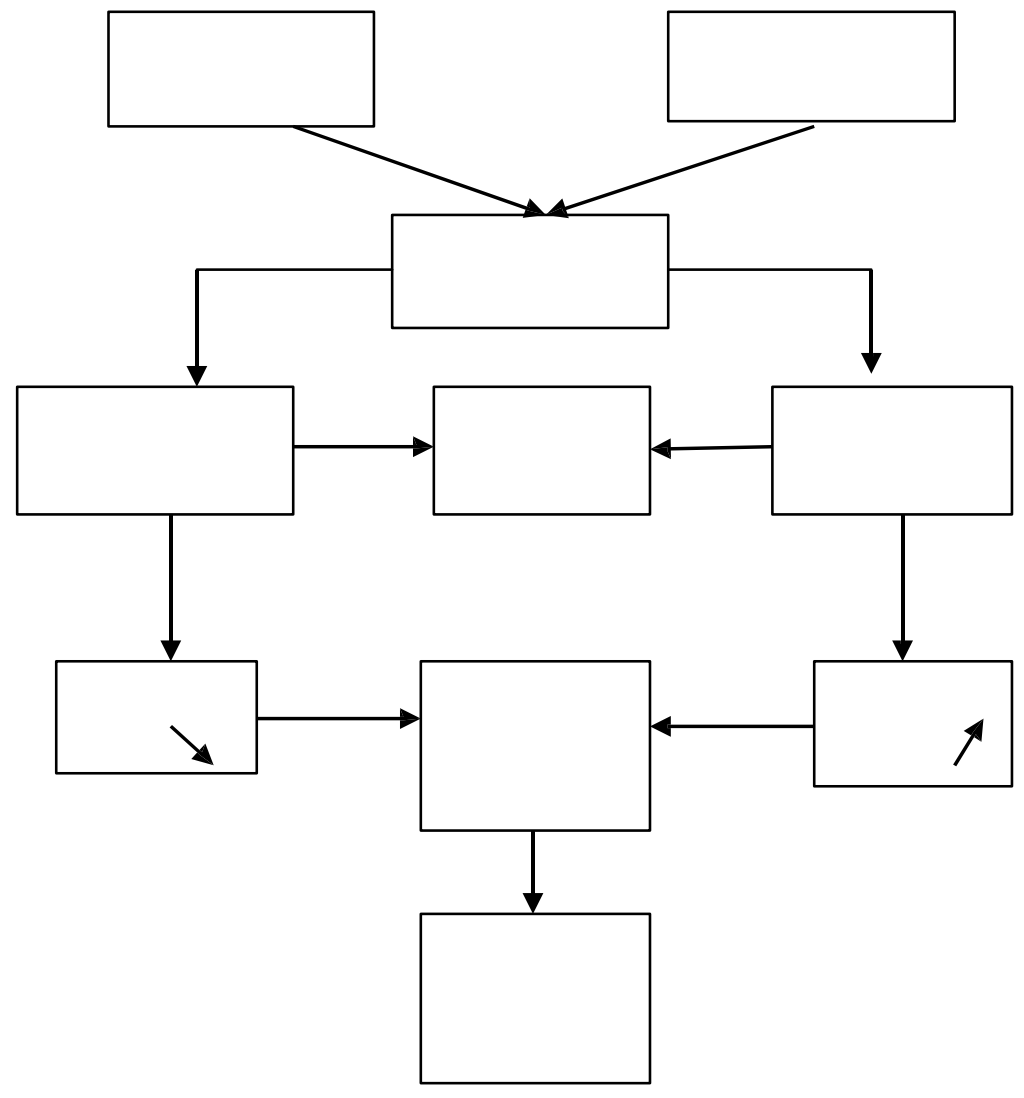


Jurnal Biosains Pascasarjana Vol. 21 (2019) pp

(C) (2019) Sekolah Pascasarjana Universitas Airlangga, Indonesia

Defisiensi Yin Ginjal Yang Paru Menutrisi

Kulit Kepala Yin Ginjal

Rambut Rontok Berkurang

Gambar 5.2 Mekanisme Terapi pada Rambut Rontok

Dari pengamatan lidah, adanya pengaruh pemberian 5 titik akupunktur tersebut dikarenakan setiap titik memiliki fungsi masing-masing yaitu: titik Baihui (GV20) yang dapat mengusir angin dan patogen. Dapat diamati dari lidah pasien yang awalnya kaku, menjadi tidak lagi kaku. Hal ini menunjukan titik ini mampu mengusir patogen angin.

Titik Sishenchong (EX-HN 1) dapat mengatur sirkulasi $q i$ dan darah (Daosheng dan Min, 1999), dapat diamati dari lidah pasien yang awalnya pendek (susah untuk dijulurkan), menjadi panjang (mudah untuk dijulurkan). Hal ini menunjukan titik ini dapat mengatur sirkulasi qi dan darah.

Titik Akupunktur Taixi (KI3), Taichong (LV3) dan Taiyuan (LU9) adalah titik Yuan dari meridian Paru, Hati dan Ginjal. Titik Yuan adalah tempat terpancarnya Qi dari meridian, Qi dua kali lebih kuat, titik Yuan dapat digunakan untuk mengatur fungsi organ internal (Gongwang, 2006). Namun secara khusus titik Taixi (KI3) memiliki fungsi untuk tonifikasi Yin ginjal, dapat diamati dari lidah pasien yang terdapat fisur (retakan) di tengah lidah, fisur menjadi berkurang.

Titik Taichong (LV3) (Lee, et al., 2015) dan Taiyuan (LU9) (Xu, 2004) memiliki fungsi untuk mengeliminasi angin dan panas dari Paru dan Hati. Dapat diamati dari Otot lidah yang tadinya kaku, berwarna merah, terdapat banyak papilla, menjadi tidak kaku, berwarna pink segar dan papilla sedikit berkurang.. Lidah yang awalnya terdapat selaput putih, menjadi tidak ada selaput.

Menurut sebuah penelitian (Jun, 2015), akupunktur dapat membantu 
Jurnal Biosains Pascasarjana Vol. 21 (2019) pp

(C) (2019) Sekolah Pascasarjana Universitas Airlangga, Indonesia

mengurangi kerontokan rambut dengan

mengurangi serangan $\mathrm{T} 1$ pada rambut.

Selain itu, juga merangsang folikel

rambut dan mengaktifkan sirkulasi

darah. Sebuah penelitian baru

menunjukkan bahwa akupunktur

mengurangi degranulasi sel mast di

dermis yang dilaporkan menjadi

kemungkinan penyebab perubahan

patologis yang menyebabkan alopecia.

\section{DAFTAR PUSTAKA}

Abdurachman. 2016. Mudah Akupunktur Melalui Anatomi. Surabaya: Arti Bumi Intaran

Arisandi, D. 2014. Hubungan Perawatan Dengan Kesehatan Rambut Mahasiswi Yang Menggunakan Kerudung Di Jurusan Kesejahteraan Keluarga Fakultas Teknik Universitas Negeri Padan. Padang: Universitas Negeri Padang

Boldrin, K. 2010. Androgenetic Alopecia: Exploring Causes, Psychological Effects, With Western and Chinese Medicine Approach: World Medicine Institute Biomed Research Paper. pp:1-15

Chan, D., and Ducic, Y. 2015. An Update on Hair Restoration: Journal of Aesthetic \& Reconstructive Surgery Vol. 1 No. 1: 8
Chun, P. 1995. Acupuncture treatment of common baldness: Journal of Chinese Medicine.

Dahlan, S. 2016. Besar Sampel dalam Penelitian Kedokteran \& Kesehatan. Jakarta: Epidemiologi Indonesia

Daosheng, L., and Min, S. 1999. Acupuncture-Moxibustion: People's Medical

Publishing House

Eliev, E. 1999. Acupuncture in Dermatology. New York: Elsevier Science Elsevier. 2009. Alopecia: Mosby's Medical Dictionary, 8th edition

França, K., Rodrigues, T.S., Ledon, J., Savas, J., Chacon, A. 2013. Comprehensive Overview and Treatment Update on Hair Loss: Journal of Cosmetics, Dermatological Sciences and Applications, pp. 1-8

Gongwang, L. 2006. Clinical Acupuncture and Moxibustion: China Press

Guerrero, A. R., and Kahn, M. 2011. Alopecias. Universidad De Los Andes pp. 775

Hutapea, S., dan Rosita, C. 2011. Telogen Efluvium. Surabaya: Berkala Ilmu Kesehatan Kulit \& Kelamin Vol. 23 No.1

Jiang, W., and Liu, W. 2006. The Treatment of Alopecia with Acupuncture and

Related Techniques: Journal of Chinese Medicine.

Jie, S.K. 1997. Dasar Teori Ilmu Akupuntur Identifikasi dan Klasifikasi Penyakit. 
Jurnal Biosains Pascasarjana Vol. 21 (2019) pp

(C) (2019) Sekolah Pascasarjana Universitas Airlangga, Indonesia

Jakarta: Grasindo pp. 14-166

Jie, S.K. 2010. Ilmu Titik Akupunktur.

Singapore : TCM Publication

Jun, J.H., Lee, H.W., Lee, J.A., Lim, H.J., Lim, H.S., and Lee, M.S. 2015. Acupuncture for Treating Alopecia Areata: a protocol of systematic review of randomised clinical trials: BMJ Open

Lanzafame, R.J., Blanche, R.R.,Bodian, A.B., Chiacchierini, R.P., Fernandez- Obregon, A and Kazmirek, E.R.. 2013. The Growth of Human Scalp Hair Mediated by Visible Red Light Laser and LED Sources in Male: Lasers in Surgery and Medicine 45:487-495Wiley Periodicals, Inc.

Lee, S.H., and Cho, M.R. 2015. A Philological Study on the Pathology, Acupuncture and Moxibustion of Alopecia: The Acupuncture Vol. 32 No.

2 KAMMS. Korean Acupuncture \&Moxibustion Medicine Society.

Lee, W.S., and Lee, H.J. 2012.

Characteristics of Androgenetic Alopecia in Asian.

Korea: Ann Dermatol Vol. 24, No. 3

Legiawati, L. 2013. Alopesia Androgenetik. Jakarta: MDVI Vol. 40 No.2

Olszewska, M., Warszawik, O., Rakowska, A., Słowińska, M., Rudnicka, L.2010. Methods Of Hair Loss Evaluation In Patients With Endocrine Disorders. Poland: Endokrynologia Polska/Polish Journal of Endocrinology

Paramita, K., Listiawaan, M.Y., Rahmawati. 2015. Gambaran Dermoskopik Pasien Alopesia. Surabaya: BIKKK - Berkala
Ilmu Kesehatan Kulit dan Kelamin Periodical of Dermatology and Venereology Vol.27/No.3

Patil, S.M., Sapkale, G.N., Surwase, U.S., Bhombe, B.T. 2010. Herbal Medicine as an Effective Therapy in Hair Loss. India: Research Journal of Pharmaceutical, Biological and Chemical Sciences Vol. 1 Issue 2

Pramitha, R.J., Wiryawan, I.G.N.S., dan Linawati, N.M. 2013. Pharmacotherapy Alopecia Androgenetic In Men: E-Jurnal Medika Udayana pp. 515-534

Pratiwi, P.D., Wiryawan, S., Linawati, N.M., Rusyati, N.L.M. 2013. Peranan Estrogen pada Wanita dengan Alopesia Androgenetik. Bali: Universitas Udayana

Putra, I.B. 2008. Alopesia Areata.

Medan: Fakultas Kedokteran Universitas Sumatera Utara

Ramos, P.M., and Miot, H.A. 2015. Female Pattern Hair Loss: a clinical and pathophysiological Review: Anais Brasileiros de Dermatologia pp. 52954 